\title{
Study on the Problems and Countermeasures of Economic and Trade Cooperation between China and Central Asia
}

\author{
Ying Zhang \\ Xi'an International University, Xi'an, Shaanxi, 710077
}

Keywords: Economic and Trade Cooperation; Problems; Countermeasures

\begin{abstract}
With the deepening of the SCO regional economic cooperation, China's economic and trade cooperation with Central Asian countries has become closer and the opportunities and challenges have coexisted. By analyzing the current economic situation in Central Asia and the current situation of economic and trade cooperation between China and Central Asian countries, according to the existing problems in economic and trade cooperation between China and Central Asian countries, the countermeasures and suggestions are put forward.
\end{abstract}

\section{Introduction}

Central Asian countries are adjacent to the china northwest, an area of 4 million square kilometers, a population of about 60 million. Rich natural resources, known as the twenty-first century strategic energy and resource base, the market is broad, for me has important economic strategic significance. Central Asian countries and my economy is complementary, cooperation potential is huge, broad prospects. In the past eighteen years, my bilateral economic and trade relations with the Central Asian countries and the continuous development of regional economic cooperation within the framework of the Shanghai Cooperation Organization have been expanding. The scale of trade has expanded year by year. The cooperation in energy, transportation, telecommunications and minerals has been gradually deepened.

The level of continuous improvement. This paper analyzes the main problems of economic and trade cooperation between China and Central Asia by combing the economic situation and development of the Central Asian region and puts forward corresponding countermeasures.

\section{The Overall Economic Situation in Central Asia}

Central Asian economy in recent years continued to grow, the level of development differences. After the disintegration of the Soviet Union, the five Central Asian countries have chosen different economic reform models, experienced a transition from a planned economy to a market economy. Kazakhstan, Ukraine, Kyrgyzstan, the tower, the five countries have been through the early independence of the social and economic crisis, the macroeconomic generally stabilized, since 2000 to varying degrees to achieve faster economic growth.

A relatively single economic structure has not changed. After independence, the common feature of the economic development of the five countries in Central Asia is that the structure is relatively simple, with energy and raw material exports, and the manufacturing and processing industries are relatively backward. After 18 years of development, the economic structure has not changed so far. As the structural problems of economic development in Central Asian countries have not changed, the endogenous driving force of economic development is insufficient, and relatively long-term structural adjustment is needed.

Small economies, relatively closed, less affected by the financial crisis. Central Asia is less open economy, Kyrgyzstan is the only member of the World Trade Organization in Central Asia. By the international financial crisis and the first half of 2009 the international energy and raw materials 
prices lower impact of national economic growth are subject to a certain impact, but the economies of Central Asia have maintained growth. Ukraine, the soil economy has maintained a relatively high growth. Annual GDP growth in Central Asia was: Kazakhstan 1.1\%, Ukraine 8.1\%, Kyrgyzstan $2.3 \%$, tower $3.4 \%$, soil $6 \%$. This year, with the rise of the international economy, the Central Asian countries have also shown a rapid increase in the momentum of the economy.

\section{China and Central Asian Countries Economic and Trade Cooperation Status Quo}

The overall trend of bilateral trade development is good, commodity structure continues to improve.

Energy, raw material products are still the main products of China's imports, in recent years I have imported a large number of oil, natural gas, natural uranium, cotton, iron ore, copper and other non-ferrous metals. On the other hand, the export of goods has also improved, in addition to the traditional textile, clothing, daily light industrial products, the proportion of mechanical and electrical, high-tech products steadily increased (close to $40 \%$ ), to promote bilateral trade rapid growth of new impetus The With the gradual emergence of the positive effects of international financial crisis measures and the deepening of bilateral economic and technological cooperation, the gradual implementation of a number of large and medium-sized bilateral projects will further expand the scale of bilateral trade and the trade structure will continue to be optimized. Sub-national economic and trade cooperation in the huge potential for development will be further developed.

Mutual investment has been expanding and economic and technological cooperation has made remarkable progress.

China and Central Asian countries have made positive progress in economic and technological cooperation in the fields of energy, transportation, electric power, mineral industry and agriculture. A number of large-scale cooperation projects have been implemented and implemented, and China has expanded its investment scale and cooperation in Central Asia. At the same time, China and Central Asian countries continue to deepen cooperation in the field of non-resources, bilateral economic cooperation has begun to finance, agriculture, telecommunications, infrastructure construction, high-tech and other non-resource areas to expand, a series of large-scale cooperation projects are in the smooth implementation or actively in the discussion. The scale of economic and technological cooperation between China and Central Asian countries has been expanding, and the economic ties and interdependence among countries have been further enhanced. Central Asia has become a hot spot for Chinese enterprises to carry out overseas investment and economic and technological cooperation, and has great potential for cooperation.

Positive progress has been made in the SCO regional economic cooperation, and bilateral economic and trade cooperation among member countries is facing new opportunities.

Since the establishment of the Shanghai Cooperation Organization (SCO) for nine years, economic cooperation, like security cooperation, has constituted two important "wheels" for organizational development. According to the approval of the State Council, China will step forward the three-step approach to promote the process of regional economic cooperation of Shanghai Cooperation Organization, that is, to promote trade and investment facilitation, deepen economic and technological cooperation, and propose and gradually establish the near, medium and long-term of the Shanghai Cooperation Organization Free Trade Zone aims.

\section{The Main Problems of Economic and Trade Cooperation between China and Central Asia}

In some countries in Central Asia, investment policy changes are more arbitrary, and government supervision is not enough. Some law enforcement departments also have major barriers such as lax enforcement, discrimination against foreign investors or non-action, such as customs clearance, technical and trade in Kazakhstan's foreign trade. The current labor policy on the quota of foreign labor, the degree of education, professional level, working life and so put forward stringent requirements, and the local labor technology level is generally low, often difficult to adapt to the 
needs of Chinese enterprises. In the discussion of enterprises generally reflect that this policy on labor visas, corporate recruitment of a greater impact.

Cargo transportation mainly relies on roads and railways, and rail transport there are different rail standards, each section of the transport line operating the main different round-going cargo volume imbalance and other issues. Customs clearance is also inefficient, and port cargo traffic has been greatly affected.

Kazakhstan and Kyrgyzstan's financial services industry is not developed, to some extent affected the bilateral investment and trade cooperation. To Kazakhstan, for example, one, both local currency billing accounted for a small proportion of RMB settlement accounted for less than $2 \%$ of the trade summary. Second, the two sides of the local currency settlement is still taking agents, clearing banks and NRA accounts and other means, has not yet formed a unified network settlement system, likely to cause low settlement time, coverage is narrow, higher fees and many other inconvenience. Third, the financial regulatory policy adjustment there is uncertainty.

In recent years, China and Kazakhstan, China and Kyrgyzstan high-level exchanges, the two countries on the "Silk Road Economic Zone" initiative to respond, but also show a strong desire for common development. However, the local government in the implementation of the policy has been distorted, often set many restrictive measures, civil society, the basis of mutual trust is poor. Local people on China's development may bring territorial disputes, resources and environment issues such as concerns, but also language practices, differences in values and conflicts.

\section{Policy Recommendations}

We will make full use of the existing platforms such as the Shanghai Cooperation Organization, the AsiaInfo Summit and the Asia Cooperation Dialogue to strengthen communication and cooperation with the Eurasian Economic Union in various fields and open up a broader market space for the construction of the Silk Road economic zone. Continue to maintain coordination with the policies of all levels of government in Central Asian countries, and gradually promote mutual customs supervision and inspection and quarantine standards, promote the implementation of the WTO Agreement on Trade Facilitation, improve the transparency of technical trade measures and promote high-level visits The consensus really implemented. At the same time, we must further promote the exchanges and cooperation between civil society organizations, Chinese-funded enterprises and local people, and combine the investment and trade projects with the needs of the local people, and truly build up the foundation of mutual trust at all levels, especially at the grassroots level.

Give full play to the central enterprises and other key enterprises to promote the role, but also to encourage private enterprises to "go out" to enhance the international market competitiveness. Focusing on energy and chemical industry, machinery manufacturing, infrastructure and other fields, combined with the resource endowment of Central Asian countries, in accordance with the industrial chain division of labor and related industries layout, to strengthen the guidance of enterprises to go out to promote the implementation of different sectors of business differentiation. Innovation and foreign investment cooperation, promote major projects "cross-industry, cross-sectoral" investment, driven technology, equipment, standards and services to go out to achieve the cement steel, processing and other industries transfer.

At present, China and the Central Asian countries signed a currency swap agreement, but has not yet formed a RMB international settlement system. It should actively promote the mutual settlement of local currency accounts, the RMB transfer of the settlement. Strengthen cooperation with Kazakhstan, Kyrgyzstan and other countries in the financial trade, and clear the RMB clearing channels, reduce the threshold of loan access. Through the consultation to build financial settlement services platform, improve the payment and settlement of the relevant policy arrangements and the region within the joint billing stage, bank card network interconnection, and gradually establish a unified payment and settlement network system.

Central Asian countries are generally stable, but the political risks in some areas can not be ignored. The local government and the public on the Chinese enterprises there are "predatory 
investment" misunderstanding and resulting in some social risks can not be ignored. In addition, all kinds of tax, investment, industry and other aspects of policy uncertainty factors still exist. Therefore, enterprises should be fully familiar with the policy environment of investment countries, take the initiative to take social responsibility and strengthen self-discipline at the same time, strengthen the local community, the news media, non-governmental organizations to fully communicate with each other, to maximize the foreign investment in the process of trade risk. The relevant government departments, industry organizations have to do a good job in investment risk assessment, to provide the appropriate risk warning services.

\section{References}

[1] Martha Briul O Carter, Li Weijian translation. Central Asia's second chance [M]. Beijing: Current Affairs Press, 2007.

[2] Cao Yan. Xinjiang and Central Asian countries economic and trade cooperation in the main problems and countermeasures [J]. Modern business, 2015 (05)

[3] Feng Yongping, Yao Zhipeng. The geopolitical game in Central Asia and China's strategic choice [J]. Journal of Shanghai Business College, 2009 (6)

[4] Li Dawei. China and the five countries in the economic and trade cooperation status quo, problems and countermeasures [J]. Macroeconomic management, 2014 (01) 